\title{
The clinical application of array CGH for the detection of chromosomal defects in 20,126 unselected newborns
}

\author{
Sang-Jin Park' , Eun Hye Jung ${ }^{1}$, Ran-Suk Ryu ${ }^{1}$, Hyun Woong Kang ${ }^{2}$, He Doo Chung ${ }^{3}$ and Ho-Young Kang ${ }^{1 *}$
}

\begin{abstract}
Background: Array comparative genomic hybridization $(\mathrm{CGH})$ is a powerful tool for detecting unbalanced chromosomal alterations. To validate the usefulness of array CGH in newborn screening, we examined 20,126 unselected infants. In addition, the number of newborns analyzed with array CGH is the largest one ever reported.

Findings: A total of 20,126 unselected newborns were investigated with array CGH and cytogenetic analyses. The analyses revealed 87 cases with chromosome abnormalities. Of these, 53 cases had significant chromosome aneuploidies, including trisomy 13 , trisomy $21,47, \mathrm{XXY}$ or $45, \mathrm{X}$, and the other 34 cases presented partial chromosomal deletions or duplications.

Conclusions: In this study, we show that array CGH is an appropriate tool for the screening of chromosomal abnormalities in newborns, especially for the infants without distinct clinical features.
\end{abstract}

Keywords: Array CGH, Newborns, Chromosome abnormality

\section{Background}

Array Comparative Genomic Hybridization (CGH) was developed as a screening strategy for detecting genomewide DNA copy number changes and many groups have studied the clinical applications of array CGH in both prenatal and postnatal settings [1-5]. Chromosomal abnormalities are a major cause of congenital and developmental abnormalities in human genetic diseases, associated with dysmorphic features, mental retardation and developmental delays, as well as multiple congenital anomalies. The most common chromosome abnormalities in newborns are trisomy 21 and sex chromosome abnormalities. The early diagnosis of these chromosomal disorders is very important to achieve optimal management and treatment [6,7]. The International Standard Cytogenomic Array (ISCA) Consortium published a consensus statement on the use of chromosomal microarray as a first tier diagnostic test in the evaluation of individuals with developmental delays and/or congenital anomalies [4]. Our group successfully developed and validated a bacterial

\footnotetext{
* Correspondence: ceo@mgmed.com

'MG MED, Inc., 60-24, Gasan-dong, Seoul, Korea

Full list of author information is available at the end of the article
}

artificial chromosome (BAC)-based array CGH analysis platform including analysis software [8].

In this study, we investigated 20,126 unselected newborns with array CGH and identified 87 abnormal cases.

\section{Results}

Whole-genome array CGH analysis was performed as a first line test to screen for genomic imbalances in 20,126 unselected newborn infants (Table 1). We simultaneously performed FISH and a G-banding analysis to confirm abnormal results of array CGH data. Of 20,126 neonatal cases, $0.43 \%(87 / 20,126)$ had DNA copy number variations: 53 cases of aneuploidy, 23 deletions, and 11 duplications (Table 2). Among the 53 aneuploidies, 18 cases were autosomal aneuploidies $(18 / 20,126 ; 0.08 \%)$, and 35 cases involved sex chromosomes (35/20,126; 0.17\%). The most frequent chromosomal abnormality was trisomy 21 , and $47, \mathrm{XXY}$ was the next most common aneuploidy. Gains or losses associated with chromosomal deletion (microdeletion) or duplication (microduplication) were observed in 34 cases. For examples, 3q29 microdeletion syndrome ( $\operatorname{arr}[$ hg19] 3q29(196,412,227-197,102,739) $\times 1$ ), Cri-du-chat syndrome (arr[hg19] 5p15.2p15.3(9,458,494$9,803,306) \times 1$ ), Soto's syndrome ( $\operatorname{arr}[$ hg19] $5 \mathrm{q} 35.2 \mathrm{q} 35.3$ 
Table 1 Summary of array CGH analysis

a array CGH analysis results confirmed by Karyotyping and FISH analyses.

${ }^{b}$ All neonatal cases, collected $<0.5$ year of age, between 2010-2012.

$(176,464,673-176,795,643) \times 1), \quad$ Prader-Willi/Angelman syndrome (arr[hg19] 15q11.2(24,055,918-27,026,553) $\times 1$ ), DiGeorge syndrome (arr[hg19] 22q11.2(19,030,620-19, $861,970) \times 1$ ), Steroid sulfatase deficiency (arr[hg19] Xp22.31(7,078,532-7,676,445) $\times 1)$, Hereditary neuropathy with liability to pressure palsies (arr[hg19] 17p11.2 $(15,067,223-15,225,580) \times 1)$, and Charcot-Marie-Tooth Disease type 1 (arr[hg19] 17p11.2(15,067,223-15,225,580) $\times 3$ ). We also identified 15q11.2q12 interstitial duplication which is validated by karyotyping and FISH as 46,XY.ish $\operatorname{dup}(15)(\mathrm{q} 11.2 \mathrm{q} 12)(\mathrm{SNRPN}+)$. And Inverted duplication $15 \mathrm{q}$ case involving mosaicism and a small supernumerary marker chromosome (sSMC) were also found. We identified various microdeletion or duplication cases and the molecular cytogenetic results are shown in Figure 1.

\section{Discussion}

Microarray-based comparative genomic hybridization (array CGH) is a high-resolution and comprehensive

Table 2 Summary of abnormal cases

\begin{tabular}{|c|c|c|c|}
\hline Array CGH analysis & Cytogenetic analyses $^{a}$ & Disorder & No. cases \\
\hline & Aneuploidy & & \\
\hline Duplication of whole chr.13 & Trisomy 13 & Patau syndrome & 1 \\
\hline Duplication of whole chr.21 & Trisomy 21 & Down syndrome & 17 \\
\hline Duplication of whole chr.X & $47, X X Y$ & Klinefelter syndrome & 15 \\
\hline Duplication of whole chr.Y & $47, X Y Y$ & $X Y Y$ & 9 \\
\hline Duplication of whole chr.X & $47, X X X$ & Triple X & 8 \\
\hline Deletion of whole chr.X & $45, x$ & Turner syndrome & 2 \\
\hline \multirow[t]{2}{*}{ Deletion of whole chr.X } & $\operatorname{mos} 45, X[28] / 46, X, i(X)(p 22.3 \rightarrow q 22:: q 22 \rightarrow p 22.3)[2]$ & Turner syndrome & 1 \\
\hline & Deletion/ Microdeletion & & \\
\hline Deletion of $0.6 \mathrm{Mb}$ at $3 \mathrm{q} 29$ & 46,XY.ish del(3)(q29)(PAK2-) & $3 q 29$ microdeletion & 1 \\
\hline Deletion of $0.3 \mathrm{Mb}$ at $5 \mathrm{p} 15.2 \mathrm{p} 15.3$ & 46,XX.ish del(5)(p15.2p15.3)(D5S727-) & Cat cry syndrome & 2 \\
\hline Deletion of $0.3 \mathrm{Mb}$ at $5 \mathrm{q} 35.2 \mathrm{q} 35.3$ & 46,XY.ish del(5)(q35.2q35.3)(NSD1-) & Sotos syndrome & 1 \\
\hline Deletion of $3 \mathrm{Mb}$ at $15 \mathrm{q} 11.2$ & 46,XX.ish del(15)(q11.2q11.2)(SNRPN-) & Prader-willi/Angelman syndrome & 1 \\
\hline Deletion of $0.3 \mathrm{Mb}$ at 17p11.2 & 46,XY.ish del(17)(p11.2p11.2)(PMP22-) & HNPP & 2 \\
\hline Deletion of $0.3 \mathrm{Mb}$ at 17p11.2 & 46,XX.ish del(17)(p11.2p11.2)(PMP22-) & HNPP & 4 \\
\hline Deletion of $0.8 \mathrm{Mb}$ at $22 \mathrm{q} 11.2$ & 46,XY.ish del(22)(q11.2q11.2)(TBX1-) & DiGeorge syndrome & 2 \\
\hline Deletion of $0.6 \mathrm{Mb}$ at Xp22.31 & 46,XY.ish del(X)(p22.31p22.31)(STS-) & Steroid sulfatase deficiency & 7 \\
\hline Deletion of $53 \mathrm{Mb}$ at Xp11.2pter/ & $46, X, i(X)(q 10)$ & Sex chromosome abnormality & 1 \\
\hline \multicolumn{4}{|l|}{ Duplication of $94 \mathrm{Mb}$ at Xq10qter } \\
\hline \multirow[t]{2}{*}{ Deletion of $55 \mathrm{Mb}$ at Xq21qter } & $46, X$, del $(X)$ (q21 qter) & Sex chromosome abnormality & 2 \\
\hline & Duplication/ Microduplication & & \\
\hline Duplication of $0.3 \mathrm{Mb}$ at15q11.2 & 46,XY.ish dup(15)(q11.2q11.2)(SNRPN+) & 15q duplication & 1 \\
\hline Duplication of $0.2 \mathrm{Mb}$ at17p11.2 & 46,XY.ish dup(17)(p11.2p11.2)(PMP22+) & CMT1A & 2 \\
\hline Duplication of $0.8 \mathrm{Mb}$ at22q11.2 & 46,XY.ish dup(22)(q11.2q11.2)(COMT+) & 22q11.2 duplication & 5 \\
\hline \multirow[t]{2}{*}{ Duplication of $0.8 \mathrm{Mb}$ at22q11.2 } & 46,XX.ish dup(22)(q11.2q11.2)(COMT+) & 22q11.2 duplication & 2 \\
\hline & Small supernumerary marker chromosome & & \\
\hline Duplication of $2 \mathrm{Mb}$ at $15 \mathrm{q} 11.2 \mathrm{q} 13$ & mos 47,XX,+inv dup(15)(q11.2q13)[9]/ 46,XX[11] & Inverted duplication 15q & 1 \\
\hline
\end{tabular}




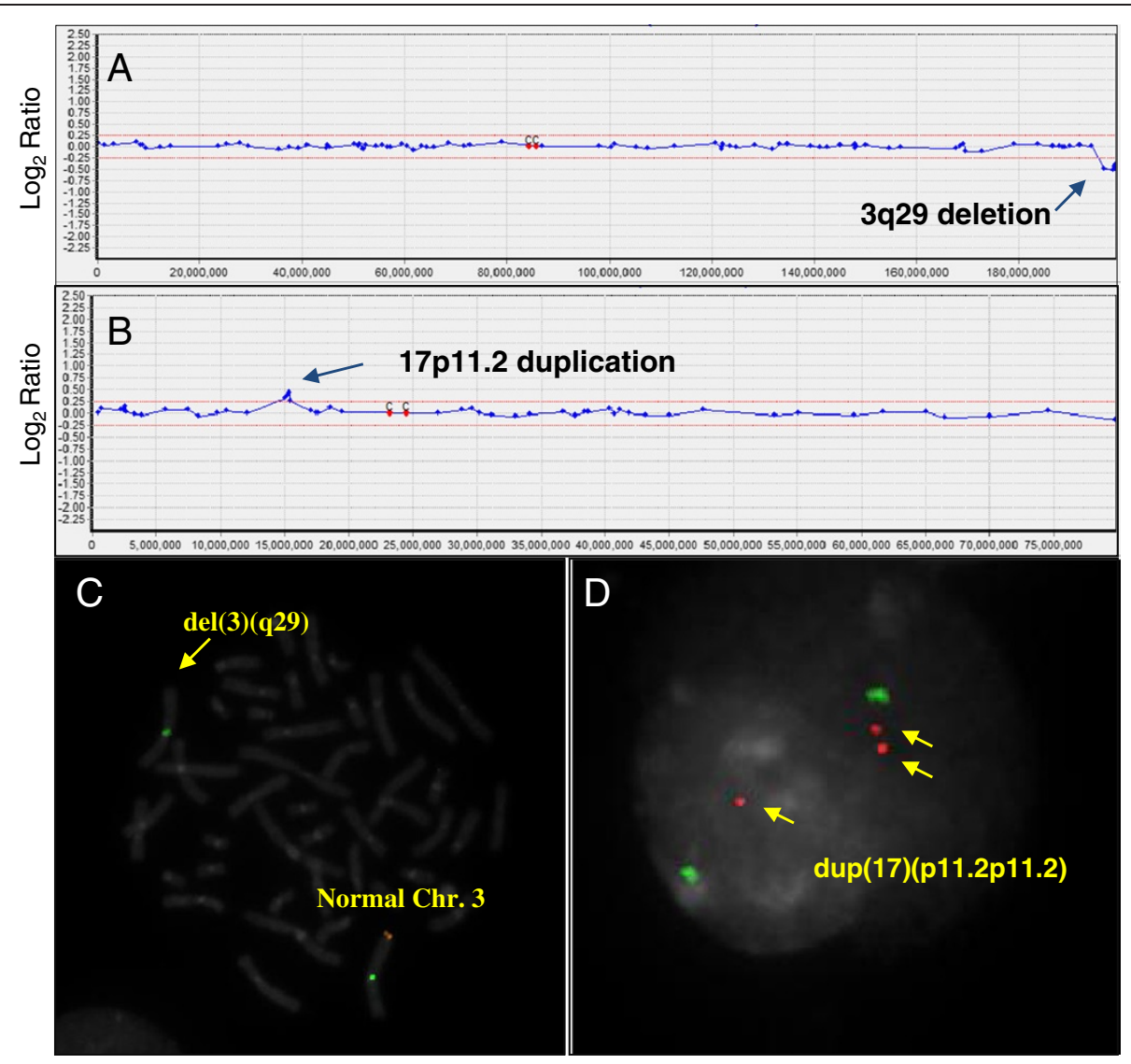

Figure 1 Examples of Array CGH and FISH results for 3q29 microdeletion case (A, C) and 17p11.2 duplication case (B, D). (A) The array $\mathrm{CGH}$ result for chromosome 3. Arrow indicates deletion of the $3 q 29$ region including the PAK2 and DLG1 genes. (B) The array CGH result for chromosome 17. Arrow indicates duplication of the CMT1A region (17p11.2). (C) FISH result analyzed with a $3 q 29$ region specific probe; arrow indicates a deletion of 3q29 region in chromosome 3. (D) FISH with 17p11.2 region specific probe; arrows indicate a duplication of $17 \mathrm{p} 11.2$ region in an interphase cell.

method for detecting both genome-wide and chromosomespecific copy-number imbalance. We have developed an array CGH analysis system for constitutional genetic diagnosis and have evaluated the suitability of our system for molecular diagnosis. Our array CGH chip consists of 1,440 non-overlapping bacterial artificial chromosome (BAC) clones, which were selected from 96,768 BAC clones constructed by the Korean Genome Project and validated by end-sequencing and FISH [8,9]. Therefore, the abnormal array $\mathrm{CGH}$ results were able to be confirmed by FISH.

Several studies of unbalanced chromosomal abnormalities in newborns have reported prevalence rates of $17 \sim 31 / 10,000$ live births [10-12]. Recently, Wellesley et al. reported that the overall frequency of unbalanced chromosome abnormalities was $0.43 \%$ (43.8/ $10,000)$ [7]. Of these, $0.36 \%$ was significant chromosome aneuploidies (T21, T18, T13, sex chromosome trisomies, and $45, \mathrm{X}$ ) and $0.07 \%$ was rare chromosome abnormalities (triploidy, other trisomies, marker chromosomes, unbalanced translocations, deletions, and duplications). Similarly, we observed abnormalities in $0.43 \%$ of 20,126 unselected newborn infants (Table 1 ). Of these, $0.26 \%(53 / 20,126)$ was characterized as significant chromosome aneuploidy. Regarding rare chromosome abnormalities, we found $0.17 \%$ of frequency which is much higher than $0.07 \%$ reported by Wellesley et al. The difference is due to different methods to detect chromosome abnormalities.

Trisomy 21 and sex chromosome aneuploidy (XXY, $\mathrm{XXX}, \mathrm{XYY}$ and $45, \mathrm{X})$ were the most frequent abnormalities (Table 2). In addition to the high frequency of diseases associated with aneuploidies, detecting chromosomal abnormalities at an early age is very important for the optimal management and treatment of the affected newborns. For example, patients with Turner syndrome (TS) can be treated with growth hormones if they are diagnosed early in life. However, many girls with TS are not diagnosed until after 10 years of age, thus resulting in delayed evaluation and treatment [13]. Although Klinefelter syndrome is mainly diagnosed in pre-pubertal males, early identification and anticipatory guidance are extremely 
helpful [14]. In Down's syndrome, early identification makes it easier to achieve the goals of treatment, particularly controlling the symptoms and managing the resulting medical conditions [15].

The chromosome deletions and duplications identified in the remaining 34 abnormal cases are associated with many clinical indications, such as developmental delays and mental retardation. The 22q11.2 deletion syndrome, also known as DiGeorge syndrome or velocardiofacial syndrome, is a genetic disorder with multisystemic manifestations, including congenital cardiac abnormalities, palatal anomalies, T-cell immunodeficiency, craniofacial features, cognitive deficits and schizophrenia [16,17]. The early diagnosis of and early intervention for psychiatric illnesses improve the long-term prognosis in individuals with schizophrenia and bipolar disorder [18]. Other treatments can usually correct critical problems, such as heart defects or low calcium levels [19].

The 5p15 deletion syndrome, known as "cat cry" or Cri du Chat syndrome, has clinical features such as low weight, microcephaly, round face, large nasal bridge, hypertelorism, epicanthal folds, downward-slanting palpebral fissures, down-turned corners of the mouth, abnormal dermatoglyphics, and a characteristic sounding cry in infancy [20]. We also identified 15q11.2 duplications. The symptoms associated with these duplications appear to range from minor (apparently normal) to highly severe mental retardation, growth retardation, and autism [21]. The early recognition of Charcot-Marie-Tooth type 1 , which is caused by a $17 \mathrm{p} 11.2$ duplication, can prevent life-threatening vincristine neurotoxicity [22].

Chromosomal disorders with developmental delays or mental retardation may not be recognized until a certain developmental stage. Some patients who have chromosomal aberrations, such as $47, \mathrm{XXY}$ or $45, \mathrm{X}$, do not exhibit clinical features until after a certain year of age. Although there are no cures for chromosomal disorders, many patients without distinct clinical features can be effectively managed and treated in the early stages of development by early diagnosis with array CGH.

In this study, we showed that our newly developed array $\mathrm{CGH}$ platform is very useful for clinical application in newborns, especially for the infants without distinct clinical features. In addition, the number of newborns analyzed with array $\mathrm{CGH}$ is the largest one ever reported.

\section{Materials and methods Patient samples}

We analyzed samples obtained from 20,126 unselected neonates who had been referred to MGMED laboratories for array CGH analysis between January 2010 and December 2012. A total of 20,126 unselected neonatal samples (16,850 peripheral blood and 3,276 cord blood) were collected for chromosome abnormality screening.
All samples were prepared for experiments using previously described methods [8]. All patient materials were obtained and evaluated with informed patient consent and with the approval of the Ethics Committees of the MGMED clinical center.

\section{Array CGH and cytogenetic analyses}

Approximately $100 \sim 200 \mathrm{ng}$ of DNA was used for the array CGH experiments, as described, with slight modifications [2]. The slides contained 1440 human BAC clones including specific loci for more than 50 chromosomal disorders. Briefly, DNA was labeled with Cy-3 and Cy-5 $\mathrm{dCTP}$ by a random priming method for $3 \mathrm{~h}$. The labeled DNA was purified, dissolved in hybridization buffer and hybridized overnight. The slides were washed several times and dried. Slide images were acquired with a GenePix4000B dual-laser scanner (Axon Instruments, Union City, CA) and analyzed with MacViewer software. Chromosome analysis was performed according to standard methods using cultured cells from peripheral blood samples obtained from the patient. FISH studies on interphase or metaphase spreads with specific probes were performed as described [8]. Cytogenetic analyses were described according to the conventions of the International System for Human Cytogenetic Nomenclature (ISCN, 2013).

\section{Competing interests}

The authors declare that they have no competing interests.

\section{Authors' contributions}

SJP drafted the manuscript and analyzed the data for the paper. HDC helped with the discussion and data summary. EHJ, RSR and HWK performed various experiments. HYK conceived of the study and approved the final manuscript. All authors read and approved the final manuscript.

\section{Acknowledgements}

We wish to thank Jeong Eun Park and Kyung Yeon Moon for their contributions to the data summary and our clinical colleagues for supporting this work. We are also grateful to other laboratory members for their enthusiastic participation.

\section{Author details}

${ }^{1} M G$ MED, Inc., 60-24, Gasan-dong, Seoul, Korea. ${ }^{2}$ MACROGEN, Inc., Seoul, Korea. ${ }^{3}$ MGMED Clinic, Seoul, Korea.

Received: 12 February 2013 Accepted: 10 April 2013

Published: 1 June 2013

\section{References}

1. Ahn JW, Mann K, Walsh S, Shehab M, Hoang S, Docherty Z, Mohammed S, Mackie Ogilvie C: Validation and implementation of array comparative genomic hybridisation as a first line test in place of postnatal karyotyping for genome imbalance. Mol Cytogenet 2010, 3:9.

2. Park SJ, Jung EH, Ryu RS, Kang HW, Ko JM, Kim HJ, Cheon CK, Hwang SH, Kang HY: Clinical implementation of whole-genome array $\mathrm{CGH}$ as a firsttier test in 5080 pre and postnatal cases. Mol Cytogenet 2011, 4:12.

3. Shaffer LG, Dabell MP, Fisher AJ, Coppinger J, Bandholz AM, Ellison JW, Ravnan JB, Torchia BS, Ballif BC, Rosenfeld JA: Experience with microarraybased comparative genomic hybridization for prenatal diagnosis in over 5000 pregnancies. Prenat Diagn 2012, 32:976-985.

4. Miller DT, Adam MP, Aradhya S, Biesecker LG, Brothman AR, Carter NP, Church DM, Crolla JA, Eichler EE, Epstein CJ, et al: Consensus statement: chromosomal microarray is a first-tier clinical diagnostic test for 
individuals with developmental disabilities or congenital anomalies. Am J Hum Genet 2010, 86:749-764.

5. Iourov IY, Vorsanova SG, Kurinnaia OS, Zelenova MA, Silvanovich AP, Yurov YB: Molecular karyotyping by array CGH in a Russian cohort of children with intellectual disability, autism, epilepsy and congenital anomalies. Mol Cytogenet 2012, 5:46

6. Boyd PA, Loane M, Garne E, Khoshnood B, Dolk H: Sex chromosome trisomies in Europe: prevalence, prenatal detection and outcome of pregnancy. Eur J Hum Genet 2011, 19:231-234.

7. Wellesley D, Dolk H, Boyd PA, Greenlees R, Haeusler M, Nelen V, Garne E, Khoshnood B, Doray B, Rissmann A, et al: Rare chromosome abnormalities, prevalence and prenatal diagnosis rates from population-based congenital anomaly registers in Europe. Eur J Hum Genet 2012, 20:521-526.

8. Choe J, Kang JK, Bae CJ, Lee DS, Hwang D, Kim KC, Park WY, Lee JH, Seo JS: Identification of origin of unknown derivative chromosomes by arraybased comparative genomic hybridization using pre- and postnatal clinical samples. J Hum Genet 2007, 52:934-942.

9. Kim JI, Ju YS, Park H, Kim S, Lee S, Yi JH, Mudge J, Miller NA, Hong D, Bell $\mathrm{CJ}$, et al: A highly annotated whole-genome sequence of a Korean individual. Nature 2009, 460:1011-1015.

10. Hamerton JL, Canning N, Ray M, Smith S: A cytogenetic survey of 14,069 newborn infants. I. Incidence of chromosome abnormalities. Clin Genet $1975,8: 223-243$

11. Dolk H, Loane M, Garne E: The prevalence of congenital anomalies in Europe. Adv Exp Med Biol 2010, 686:349-364.

12. Jacobs PA, Browne C, Gregson N, Joyce C, White H: Estimates of the frequency of chromosome abnormalities detectable in unselected newborns using moderate levels of banding. J Med Genet 1992, 29:103-108.

13. Rivkees SA: Ending the late diagnosis of Turner syndrome through a novel high-throughput assay. Pediatr Endocrinol Rev 2012, 9(Suppl 2):698-700.

14. Paduch DA, Fine RG, Bolyakov A, Kiper J: New concepts in Klinefelter syndrome. Curr Opin Urol 2008, 18:621-627.

15. Ness S, Rafii M, Aisen P, Krams M, Silverman W, Manji H: Down's syndrome and Alzheimer's disease: towards secondary prevention. Nat Rev Drug Discov 2012, 11:655-656.

16. Bassett AS, Chow EW, AbdelMalik P, Gheorghiu M, Husted J, Weksberg R: The schizophrenia phenotype in $22 q 11$ deletion syndrome. Am J Psychiatry 2003, 160:1580-1586.

17. Gothelf D, Frisch A, Michaelovsky E, Weizman A, Shprintzen RJ: Velo-cardiofacial syndrome. J Ment Health Res Intellect Disabil 2009, 2:149-167.

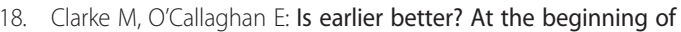
schizophrenia: timing and opportunities for early intervention. Psychiatr Clin North Am 2003, 26:65-83.

19. Yu S, Graf WD, Shprintzen RJ: Genomic disorders on chromosome 22. Curr Opin Pediatr 2012, 24:665-671.

20. Cerruti Mainardi P: Cri du chat syndrome. Orphanet J Rare Dis 2006, 1:33.

21. Abdelmoity AT, LePichon JB, Nyp SS, Soden SE, Daniel CA, Yu S: 15q11.2 proximal imbalances associated with a diverse array of neuropsychiatric disorders and mild dysmorphic features. J Dev Behav Pediatr 2012, 33:570-576.

22. Naumann R, Mohm J, Reuner U, Kroschinsky F, Rautenstrauss B, Ehninger G: Early recognition of hereditary motor and sensory neuropathy type 1 can avoid life-threatening vincristine neurotoxicity. Br J Haematol 2001, 115:323-325.

doi:10.1186/1755-8166-6-21

Cite this article as: Park et al: The clinical application of array CGH for the detection of chromosomal defects in 20,126 unselected newborns. Molecular Cytogenetics 2013 6:21.

\section{Submit your next manuscript to BioMed Central and take full advantage of:}

- Convenient online submission

- Thorough peer review

- No space constraints or color figure charges

- Immediate publication on acceptance

- Inclusion in PubMed, CAS, Scopus and Google Scholar

- Research which is freely available for redistribution

Submit your manuscript at www.biomedcentral.com/submit
( Biomed Central 